University of Nebraska - Lincoln

DigitalCommons@University of Nebraska - Lincoln

Industrial and Management Systems

Industrial and Management Systems

Engineering Faculty Publications

Engineering

1995

\title{
Force-endurance relationship: does it matter if gloves are donned?
}

Ram R. Bishu

University of Nebraska-Lincoln, RBISHU1@UNL.EDU

Byungjoon Kim

University of Nebraska-Lincoln

Glen Klute

NASA

Follow this and additional works at: https://digitalcommons.unl.edu/imsefacpub

Bishu, Ram R.; Kim, Byungjoon; and Klute, Glen, "Force-endurance relationship: does it matter if gloves are donned?" (1995). Industrial and Management Systems Engineering Faculty Publications. 76.

https://digitalcommons.unl.edu/imsefacpub/76

This Article is brought to you for free and open access by the Industrial and Management Systems Engineering at DigitalCommons@University of Nebraska - Lincoln. It has been accepted for inclusion in Industrial and Management Systems Engineering Faculty Publications by an authorized administrator of DigitalCommons@University of Nebraska - Lincoln. 


\title{
Force-endurance relationship: does it matter if gloves are donned?
}

\author{
Ram R. Bishu and Byungjoon Kim \\ Department of Industrial Engineering, University of Nebraska, Lincoln, NE 68588-0518, USA \\ Glen Klute \\ Anthropometry and Biomechanics Laboratory, NASA, Johnson Space Center, Houston, Texas, USA
}

\begin{abstract}
The human hand is a very useful multipurpose tool in all environments. However, performance capabilities are compromised considerably when gloves are donned. This is especially true for extra-vehicular activity (EVA) gloves used in a space environment. The primary aim of this study was to establish exertion and endurance limits for specific tasks. The objective of this study was to develop grip force endurance relations. Six subjects participated in a factorial experiment involving three hand conditions, three pressure differentials, and four levels of force exertion. The results indicate that while the force that could be exerted depended on the glove, pressure differential, and the level of exertion, the endurance time at any exertion level depended just on the level of exertion expressed as a percentage of maximum exertion possible at that condition. The impact of these findings for practitioners as well as theoreticians is discussed.
\end{abstract}

Keywords: gloves, exertion and endurance limits

\begin{abstract}
Almost all industrial tasks require the use of gloves to protect the hand from the environment. Whether this environment consists of sharp tools, extreme temperatures, or harsh chemicals, gloves are donned to protect the hand. While the safety function of gloves has never been in any doubt, understanding of the effect of gloves on task performance is muddled at best. There is some conflicting evidence on the effects of gloves on performance, with some studies reporting performance decrement while others report performance improvement with gloves. However, the conflict associated with providing hand protection while permitting adequate hand functioning has been widely recognized in glove design. This is true for both space sector gloves and commercial sector gloves.

Many articles have been published in the area of the effect of gloves on task performance (see for example Lyman and Groth, 1958; Bradley, 1969a, b; Cochran et al, 1986; Adams and Peterson, 1988; Mital et al, 1994). In summary, the effect of gloves on performance capabilities is that gloves may decrease some aspects of performance, and that the performance decrement is a function of glove material characteristics. While most of the published studies have been on commercial gloves, the only studies on EVA gloves have been the investigations performed by O'Hara et al (1988) and Bishu et al (1993a, b). O'Hara et al (1988) studied two levels of hand conditions (gloved and barehanded), two levels of pressure differential ( 0 psid and 4.3 psid; $0 \mathrm{kPa}$ and $29.6 \mathrm{kPa}$ ), and three levels of hand size
\end{abstract}

(small, medium and large). Bishu et al (1993a, b) studied the effects of EVA gloves at different pressures on human hand capabilities. A factorial experiment was performed in which three types of EVA gloves were tested at five pressure differentials. The independent variables tested in this experiment were gender, glove type, pressure differential, and glove make. Six subjects participated in an experiment where a number of performance measures, namely grip strength, pinch strength, time to tie a rope, and the time to assemble a nut and bolt, were recorded. Tactile sensitivity was also measured through a two-point discrimination test. The salient results were:

(1) With EVA gloves strength is reduced by nearly $50 \%$.

(2) Performance decrements increase with increasing pressure differential.

(3) With EVA gloves there is a considerable reduction in dexterity.

(4) Dexterity performance decrements increase with increasing pressure differential.

EVA activities involve certain levels of hand exertions for periods of time. Therefore, two issues are relevant here: the extent of exertion and the time of exertion. The studies discussed above have addressed the extent of exertion. However, an important question that needs to be addressed, but which has not been, is how long can a person sustain a level of exertion in performing EVAs. This deals with muscular fatigue 
and related issues. O'Hara et al (1988) attempted to measure fatigue through shifts in the median frequency of the EMG power spectrum, but the results were uninterpretable. A number of researchers have used the functional relationship between force exerted by a muscle group and the time of endurance as a predictor of muscle fatigue (Rohmert, 1960; Monod and Scherrer, 1965). In general, endurance time increases with decreasing force. Bishu et al (1990) have used endurance time for evaluating container handles. The objective of this investigation was to answer the question 'How long can a person sustain a level of exertion in performing EVA activity?'. The aim was to develop force time relationships for a variety of EVA glove-pressure combinations. It was expected that such relations would generate some information relating to static muscle fatigue.

\section{Methods}

\section{Subjects}

Six subjects (three males and three females) participated in this experiment. Their participation was voluntary.

\section{Independent variables}

The independent variables tested in this experiment were gender, glove type, pressure differential, and level of cxertion. Three levels of pressure differential were used in this experiment ( 0 psid, 4.3 psid, and $8.3 \mathrm{psid})$. The intent was to develop a force-endurance relationship at each pressure, for each glove. Three different gloves were tested here: the current 3000 series gloves in training astronauts in the weightless environment training facility (referred to hereafter as Glove $\mathrm{C}$ ), and two advanced developmental gloves (referred to hereafter as Gloves A and B). These gloves were an assembly of three different kinds of glove: an internal comfort glove, a pressurizable rubber glove, and an external glove. Typically, an astronaut dons these three layers of gloves. The three types of glove tested here differed in the middle and external layer. Four levels of exertion were used here: $100 \%, 75 \%$, $50 \%$ and $25 \%$ of maximal voluntary contraction. The performance measure was the endurance time, or the time to which a person could sustain the level of exertion. To summarize, the independent variables with their respective levels were:

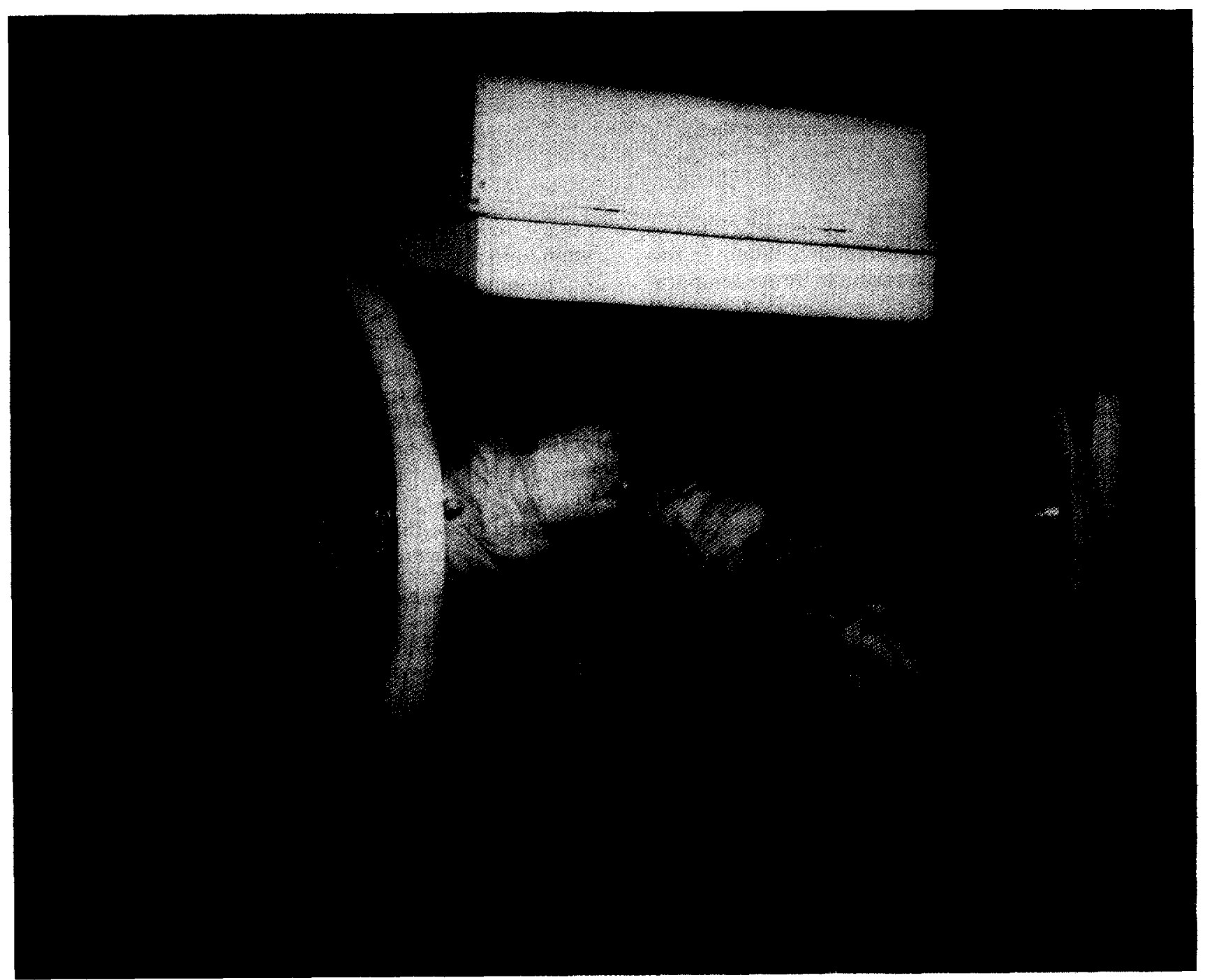

Figure 1 


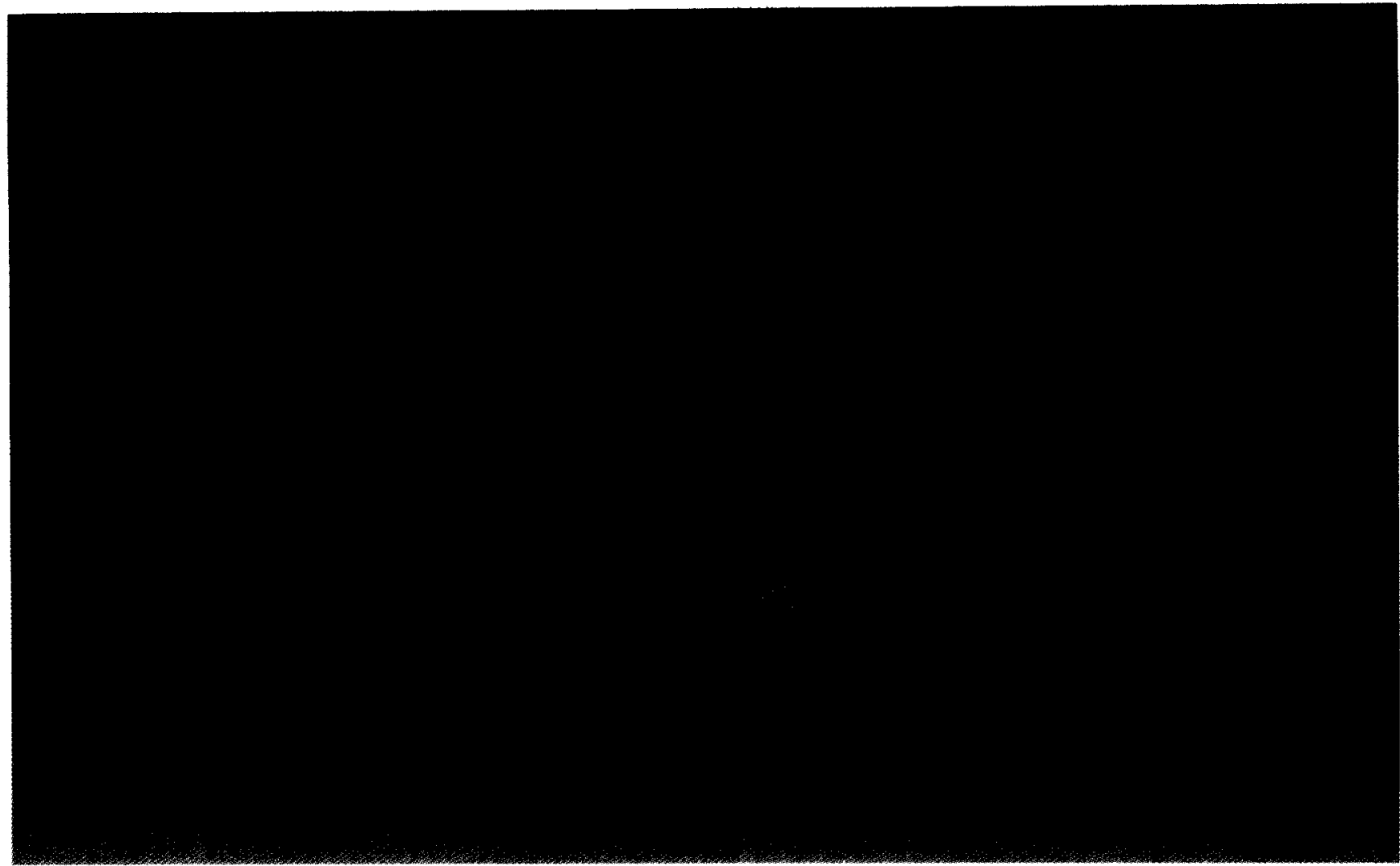

Figure 2

(1) gender: male and female;

(2) pressure: $0,4.3$ and 8.3 psid $(0,29.6$ and $57.2 \mathrm{kPa})$;

(3) glove condition: $\mathrm{A}, \mathrm{B}, \mathrm{C}$ and barehand;

(4) level of exertion: $100 \%, 75 \%, 50 \%$ and $25 \%$.

\section{Glove box}

The tests were conducted inside a glove box. The glove box is cylindrical in shape, approximately $2 \mathrm{ft}(600 \mathrm{~mm})$ in diameter and $4 \mathrm{ft}(1200 \mathrm{~mm})$ in length, with an internal volume of $13 \mathrm{ft}^{3}\left(0.37 \mathrm{~m}^{3}\right)$ (Figure 1). On each side of the glove box were two end caps, made of Plexiglas. About midway along the axis of the glove box were two 6 in $(150 \mathrm{~mm})$ circular openings in the cylinder wall, placed shoulder width apart, which provided access and an attachment point for the EVA glove and arm assemblies. The glove box was connected to a vacuum pump and could be evacuated to any desired pressure level. There was a gauge on the outer cylinder wall calibrated to read the pressure differential. The set up for this experiment was similar to the one described in Bishu and Klute (1993). Figure 2 shows the types of gloves tested.

\section{Procedure}

There were 36 treatment conditions in this experiment. The order of presentation of the conditions was randomized for each subject. Initially the maximum voluntary contraction (MVC) for each glove-pressure combination was measured using a Jamar hand dynamometer. The dynamometer was wired to a Teac recorder. The four levels of exertion at any glovepressure combination were computed with respect to the MVC at that combination. A trial consisted of the following steps:

(1) The exertion level for the 'condition of the day' was first calculated.

(2) The glove box was pressurized to the 'condition of the day'.

(3) The subject donned the relevant EVA for the 'condition of the day' and exerted to the computed level of gripping force on the Jamar hand dynamometer.

(4) The subject maintained the level of exertion for as long as he/she could, before quitting voluntarily.

(5) The endurance time was recorded through the Teac recorder and a stopwatch.

A $24 \mathrm{~h}$ rest period was followed between trials. As a result, the experiment lasted for 36 days in all.

\section{Results}

A multifactor analysis of variance (ANOVA) was performed on the data for two dependent measures, endurance time and exertion force. The ANOVA summary for exertion force is given in Table 1 , while the corresponding summary for exertion level is given in Table 2. Table 3 presents the mean and standard deviation of force values at all the treatment conditions, while Table 4 shows the corresponding endurance time values for all the treatment conditions.

It is interesting to note that while all the main effects and the first-order interactions are significant for exertion force, the endurance time seems to depend only on the exertion level. 
Table 1 Means and standard deviations for exertion force (lb) 1 lb = $0.453 \mathrm{~kg}$

\begin{tabular}{ccc}
\hline Effects & Mean & SD \\
\hline Gender & & \\
Male & 35.53 & 21.45 \\
Female & 21.84 & 10.69 \\
Subject & & \\
1 & 39.17 & 20.25 \\
2 & 46.97 & 24.39 \\
3 & 21.66 & 9.48 \\
4 & 17.59 & 7.93 \\
5 & 25.57 & 12.02 \\
6 & 23.85 & 10.98 \\
Exertion & & \\
25 & 13.31 & 5.05 \\
50 & 24.17 & 9.86 \\
75 & 35.36 & 15.29 \\
100 & 46.86 & 21.54 \\
Glove & & \\
A & 30.24 & 20.98 \\
B & 29.64 & 17.41 \\
C & 27.66 & 17.33 \\
Pressure & & \\
0 & 34.34 & 21.69 \\
4.3 & 26.69 & 16.27 \\
8.3 & 25.13 & 14.89 \\
\hline
\end{tabular}

Table 2 Means and standard deviations for endurance (s)

\begin{tabular}{crr}
\hline & \multicolumn{2}{c}{ Endurance } \\
\cline { 2 - 3 } Effects & Mean & SD \\
\hline Gender & & \\
Male & 122.20 & 149.35 \\
Female & 110.31 & 163.65 \\
Subject & & \\
1 & 121.34 & 108.94 \\
2 & 72.75 & 67.98 \\
3 & 172.53 & 216.15 \\
4 & 170.41 & 221.10 \\
5 & 109.94 & 152.50 \\
6 & 50.59 & 50.20 \\
Exertion & & \\
25 & 293.77 & 221.39 \\
50 & 85.29 & 47.29 \\
75 & 53.89 & 39.29 \\
100 & 32.08 & 46.87 \\
Glove & & \\
A & 113.22 & 166.39 \\
B & 107.64 & 136.59 \\
C & 133.75 & 170.02 \\
Pressure & & \\
0 & 124.72 & 163.28 \\
4.3 & 108.60 & 167.15 \\
8.3 & 11.70 & \\
\hline & & \\
\hline
\end{tabular}

\section{Exertion force results}

Figure 3 shows a plot of the exertion level $\times$ glove interaction for the exertion force. It is apparent that the force exerted at the exertion levels tested is significantly higher for bare hand than for gloved hand. This is expected, as gloves tend to reduce grip strength. Figure 4 shows the exertion level $\times$ pressure interaction for the exertion force. The difference between $0 \mathrm{psi}$ and the other two pressures is significant, with the greater forces being exerted at 0 psid than at 4.3 and 8.3 psid.
Table 3 ANOVA for endurance

\begin{tabular}{lccc}
\hline & DF & Sum of square & F ratio \\
\hline Gender & 1 & 6792.52 & 0.67 \\
Subject & 4 & 389023.96 & 9.57 \\
Exertion level & 3 & 2085318.44 & 68.37 \\
Glove & 2 & 20698.92 & 1.02 \\
Pressure & 2 & 13829.63 & 0.68 \\
Gender $\times$ Subject & 0 & 0 & NA \\
Gender $\times$ Exertion & 3 & 4297.18 & 0.14 \\
Gender $\times$ Glove & 2 & 69131.10 & 3.40 \\
Gender $\times$ Pressure & 2 & 11809.04 & 0.58 \\
Subject $\times$ Exertion & 12 & 463827.44 & 3.80 \\
Subject $\times$ Glove & 8 & 147503.30 & 1.81 \\
Subject $\times$ Pressure & 8 & 51021.87 & 0.63 \\
Exertion $\times$ Glove & 6 & 26571.86 & 0.44 \\
Exertion $\times$ Pressure & 6 & 66077.28 & 1.08 \\
Glove $\times$ Pressure & 3 & 2481.10 & 0.08 \\
\hline
\end{tabular}

NA: not applicable

Table 4 ANOVA for exertion force

\begin{tabular}{lccc}
\hline & DF & Sum of square & F ratio \\
\hline Gender & 1 & 7889.74 & 372.90 \\
Subject & 4 & 10628.74 & 125.59 \\
Exertion Level & 3 & 26647.59 & 419.83 \\
Glove & 2 & 244.45 & 5.78 \\
Pressure & 2 & 2949.85 & 69.71 \\
Gender $\times$ Subject & \multicolumn{3}{c}{0} \\
Gender $\times$ Exertion & 3 & 2266.04 & NA \\
Gender $\times$ Glove & 2 & 98.99 & 2.70 \\
Gender $\times$ Pressure & 2 & 346.25 & 8.18 \\
Subject $\times$ Exertion & 12 & 3131.93 & 12.34 \\
Subject $\times$ Glove & 8 & 370.25 & 2.19 \\
Subject $\times$ Pressure & 8 & 1200.37 & 7.09 \\
Excrtion $\times$ Glove & 6 & 1131.10 & 0.89 \\
Exertion $\times$ Pressure & 6 & 402.78 & 3.17 \\
Glove $\times$ Pressure & 3 & 356.07 & 5.61 \\
\hline
\end{tabular}

NA: not applicable

Figure 5 shows a plot of the glove $\times$ pressure interaction for the exertion force. Barehanded force is much greater than the gloved hand force. Among the two developmental gloves testcd here, subjects seem to exert greater force with glove $B$ at 8.3 psid than with glove A. An explanation is in order here. Gloves A and $B$ were being designed for use at 8.3 psid whereas glove $\mathrm{C}$ was designed for use at 4.3 psid. There are some space environment advantages in working at 8.3 psid, which was the primary reason for the development of the advance developmental gloves A and B. Figure 6 shows a plot of the gender $X$ glove interaction for the exertion force. Female subjects demonstrated lower strength capabilities than male subjects, and this difference is consistent across all glove configurations tested. Figure 7 shows a plot of the gender $\times$ pressure interaction for the exertion force. Again, female subjects demonstrated lower strength capabilities than male subjects, and this difference is consistent across all the pressure differentials.

\section{Endurance time results}

Perhaps the most interesting finding of this experiment is the lack of significance of almost all factors for the endurance time. As is seen in Table 1, the subject effect and the exertion level effect are the only significant effects. Figure 8 shows a plot of the exertion level effect 


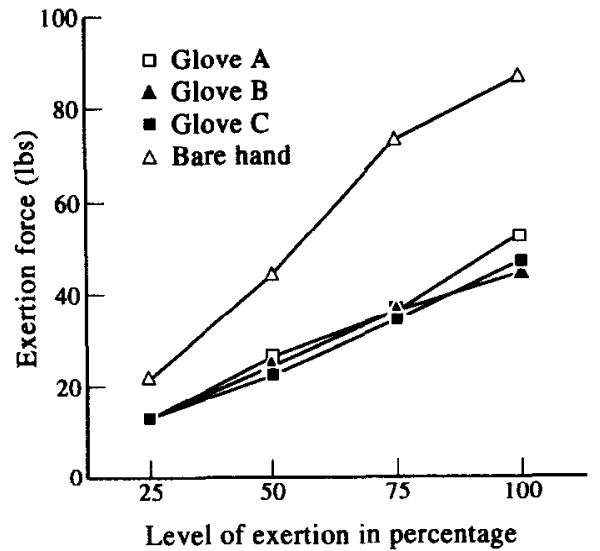

Figure 3

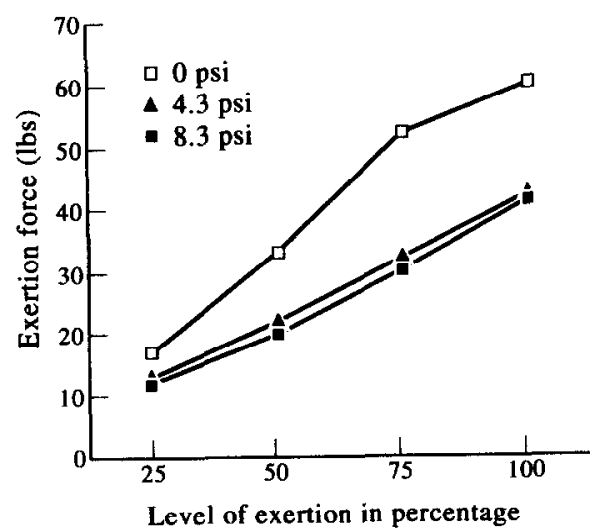

Figure 4

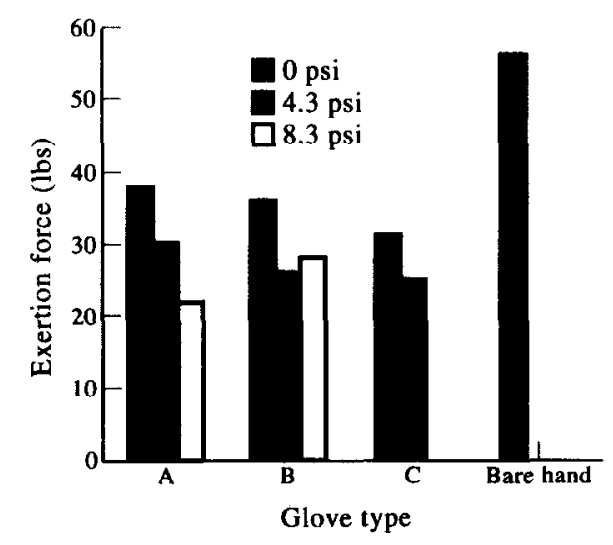

Figure 5

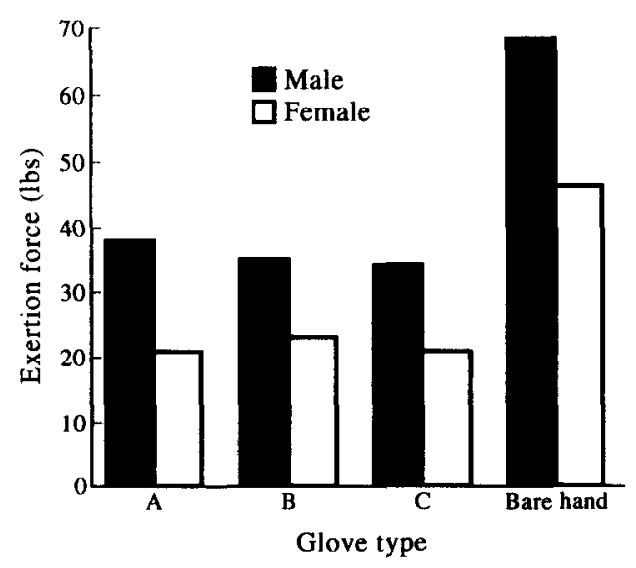

Figure 6

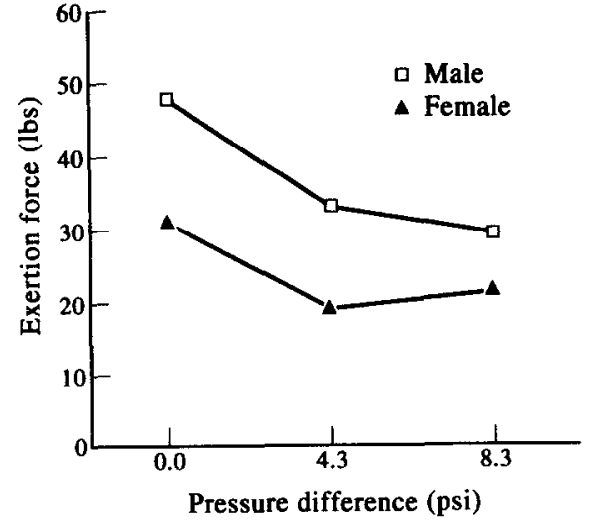

Figure 7

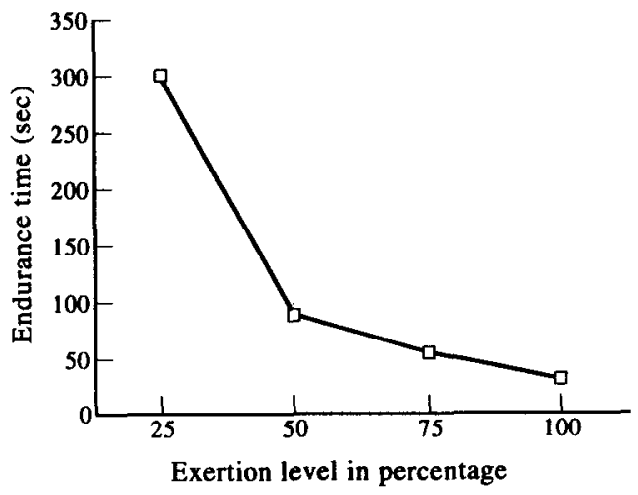

Figure 8

on the endurance time, across all glove configurations and pressure differentials. The endurance time is least at $100 \%$ exertion level, and most at $25 \%$ exertion level. As the plot in Figure 8 resembled a negative exponential relationship, a similar model was fitted to the data. The model was determined to be

$$
\begin{aligned}
& \text { Endurance time }=435.257 \mathrm{e}^{-3.0792 p}, \\
& r^{2}=0.6232
\end{aligned}
$$

where $p=$ level of exertion expressed as a ratio of absolute exertion in a configuration to the maximum exertion at that configuration. According to this equation the maximum possible endurance (at $p=0$ ) is $435.257 \mathrm{~s}$, while minimum endurance (at $p=100 \%$ ) is about $7 \mathrm{~s}$.

\section{Discussion}

Among the two dependent variables tested in this experiment, the findings on exertion force are consistent with those reported by these authors in their earlier study (Bishu and Klute, 1993). Female subjects tended to perform slower, and showed lower strength capabilities. The reduced strength capabilities of females were consistent across all pressure differential conditions, although there was a lower pressure effect on female subjects than on male subjects (see Figure 6). The fit of the glove to the hand, which was not controlled in this experiment, may have caused some of the observed gender difference. Just one pair of gloves in each glove 
condition, fitting the largest male hand, was used in this experiment. The finding that both pressure and glove reduce performance is consistent with those reported by O'Hara et al (1988) and others (Cochran et al 1986; Wang et al 1987). With gloves there is an apparent increase in grip span and an earlier pressing of fingers with each other. 'The former should increase the grip strength, while the latter should reduce the strength. It appears that the effect of increase in grip span with gloves is somewhat counteracted by the reduction in the inter-digital movements and range of motion when gloves are donned, resulting in net reduction in performance.

Perhaps the most interesting finding of this experiment is the lack of significance of almost all factors for the endurance time. A glove effect, pressure effect, glove $X$ exertion level, and pressure $X$ exertion level interaction were expected. Results indicate that subject and exertion level effects were significant. There are two explanations for this. It may have been an artefact of sample size, or due to some lack of control in the experiment. The experimental procedure was to let the subjects exert once a day, for 36 days. However, owing to scheduling constraints and other difficulties, some of the subjects performed two experimental conditions per day, on certain days. The second, and the more probable explanation, is that the physiological cost may be the same for barehand and gloved/pressurized conditions at any level of exertion. For example, let us say that a person exerts $100 \mathrm{lb}$ of grip strength at his/her $100 \%$ barehanded condition, and $80 \mathrm{lb}$ of grip strength at his/her $100 \%$ gloved condition. Judging from the results of this study, the muscular exertions of the lower and upper arm musculature may be the same for both because the observed endurance time was similar. Therefore, the fatigue can be expected to be the same for both. The same argument can be made for other levels of exertion. At $50 \%$ exertion level, the grip strength for the barehanded and gloved condition will be $50 \mathrm{lb}(22.7 \mathrm{~kg})$ and $40 \mathrm{lb}(18.1 \mathrm{~kg})$ respectively; the upper arm and lower arm musculature may again be fatiguing at the same rate, as indicated by similar endurance time. This is consistent with the findings reported by Sudhakar et al (1988). In comparing gloved and barehanded performance, the authors reported similar electromyographic activity of the lower arm muscles in both conditions, though the gloved hand resulted in reduced strength capability.

The endurance time equation developed here is similar to those determined by Rohmert (1960), Monod and Scherrer (1965). However, the endurance time is asymptotic to the abscissa in the Rohmert (1960) and Monod and Scherrer (1965) expressions, at 15\% and $14 \%$ of maximum voluntary contraction respectively, while here the maximum possible endurance is $435 \mathrm{~s}$. The finding that the endurance time depended only on the exertion level, expressed as a percentage of maximum at that glove condition, has profound significance for theoreticians as well as for practitioners. For the practitioner, prescriptions for endurance time for any activity can easily be provided by just determining the exertion level of that activity. For theoreticians, the answer to the question of 'Why should the endurance time not be dependent on pressure differentials or on the type of glove donned?' could be interesting.
In summary, endurance time can be represented by the following set of equations:

Endurance time $=a \mathrm{e}^{b p}$

where $a$ is the maximum endurance time, $b$ is the fatigue rate, and $p$ is the level of exertion, and exertion force at any exertion level $p$ can be expressed by

Exertion force $=k(G S) p$

where $G S$ is the maximum grip strength in a barehanded condition, $k$ is a hand condition factor $(k=1$ for barehanded, and $<1$ for gloved conditions), and $p$ is exertion level. With these equations, one can describe glove/pressure conditions through $k$ (the hand condition factor).

\section{Conclusion}

Performance decrements occur with gloves and with increasing pressure differential. However, the endurance time is dependent only on the exertion level expressed as a percentage of maximum exertion force in that hand condition. It is possible to develop a general exponential equation for cndurance timc, and describe the hand condition through a 'hand condition' factor. Glove hand fit was not controlled in this study and may have had an impact on the findings. More research is needed to determine the exact effects of size and glove material on performance. Such data will be invaluable to the designer of hand gloves.

\section{References}

Adams, S.K. and Peterson, P.J. 1988 'Maximum voluntary hand grip torque for circular electrical connectors' Human Factors 30 (6), $733-745$

Bishu, R. R. and Klute, G. 1993 'Investigation of the effects of extra vehicular activity (EVA) gloves on performance' NASA Technical Paper no. 3401, Johnson Space Center, NASA, Huustur, TX

Bishu, R. R., Deeb, J. M. and Myung, R. 1990 'Evaluation of handle positions using force/endurance relationship of an isometric holding task' Proc 34th Annual Meeting of the Human Factors Society Human Factors Society, Santa Monica, CA, pp 692-696

Bishu, R. R., Klute, G. and Kim, B. 1993a 'Investigation of the effects of extra vehicular activity (EVA) gloves on dexterity and tactility' Proc 37th Annual Meeting of Human Factors and Ergonomics Society Seattle, WA, October, 1993, pp 826-831

Bishu, R. R., Klute, G. and Kim, B. 1993b 'Investigation of the effects of extra vehicular activity (EVA) gloves on performance' in R. Nielson and K. Jorgensen (eds) Advances in Industrial Ergonomics and Safety $V$ Taylor \& Francis, London, pp 683-690

Bradley, J. V. 1969a 'Effect of gloves on control operation time' Human Factors 11, 13-20

Bradley, J. V. $1969 \mathrm{~b}$ 'Glove characteristics influencing control manipulability' Human Factors 11 (1), 21-36

Cochran, D. J., Albin, T. J., Bishu, R. R. and Riley, M. W. 1986 'An analysis of grasp force degradation with commercially available gloves' Proc 30th Annual Meeting of the Human Factors Society Human Factors Society, Santa Monica, CA 852-855

Lyman, J. and Groth, H. 1958 'Prehension force as a measure of psychomotor skill for bare and gloved hands' $J$ Appl Psychol $\mathbf{4 2}$ (1), $18-21$

Mital, A., Kuo, T. and Faard, H.F. 1994 'A quantitative evaluation of gloves used with non-powered hand tools in routine maintenance tasks' Ergonomics 37(2), 333-343

Monod, H. and Scherrer, J. 1965 'The work capacity of a synergic muscular group' Ergonomics 8, 329-338

O'Hara, J. M., Briganti, M., Cleland, J. and Winfield, D. 1988 Extravehicular Activities Limitations Study. Vol II: Establishment 
of Physiological and Performance Criteria for EVA Gloves - Final Report Report number AS-EVALS-FR-8701, NASA Contract no NAS-9-17702

Rohmert, W. 1960 'Ermittlung von Erholungspausen fur statische arbeit des menschen' Int $Z$ Angew Physiol Einsehl Arbeit physiol 18, 123-164

Sudhakar, L. R., Schoemarklin, R. W., Lavender, S. A. and Mares,
W. S. 1988 'The effects of gloves on grip strength and muscle activity' Proc 32nd Annual Meeting of the Human Factors Society Human Factors Society, Santa Monica, CA, pp 647-650

Wang, M. J., Bishu, R. R. and Rodgers, S. H. 1987 'Grip strength changes when wearing three types of gloves' Proc Fifth Symposium on Human Factors and Industrial Design in Consumer Products, Interface 87 Rochester, Human Factors Society, NY, pp. 349-354 